Check for updates

Cite this: Chem. Sci., 2019, 10, 6193

๑ All publication charges for this article have been paid for by the Royal Society of Chemistry

Received 12th February 2019

Accepted 11th May 2019

DOI: $10.1039 / \mathrm{c} 9 \mathrm{sc} 00731 \mathrm{~h}$

rsc.li/chemical-science

\section{Borohydride-containing coordination polymers: synthesis, air stability and dehydrogenation $\dagger$}

\author{
Kentaro Kadota, ${ }^{a}$ Nghia Tuan Duong, (D) ${ }^{\mathrm{b}}$ Yusuke Nishiyama, (D) ${ }^{\mathrm{bc}}$ Easan Sivaniah, (D) ad \\ Susumu Kitagawa ${ }^{d}$ and Satoshi Horike (D) *defg
}

\begin{abstract}
Control of the reactivity of hydride $\left(\mathrm{H}^{-}\right)$in crystal structures has been a challenge because of its strong electron-donating ability and reactivity with protic species. For metal borohydrides, the dehydrogenation activity and air stability are in a trade-off, and control of the reactivity of $\mathrm{BH}_{4}{ }^{-}$has been demanded. For this purpose, we synthesize a series of $\mathrm{BH}_{4}{ }^{-}$-based coordination polymers/metal-organic frameworks. The reactivity of $\mathrm{BH}_{4}{ }^{-}$in the structures is regulated by coordination geometry and neighboring ligands, and one of the compounds $\left[\mathrm{Zn}\left(\mathrm{BH}_{4}\right)_{2}\right.$ (dipyridylpropane)] exhibits both high dehydrogenation reactivity $\left(1.4\right.$ wt\% at $179{ }^{\circ} \mathrm{C}$ ) and high air stability (50 RH\% at $25^{\circ} \mathrm{C}, 7$ days). Single crystal X-ray diffraction analysis reveals that $\mathrm{H}^{\delta+} \ldots \mathrm{H}^{\delta-}$ dihydrogen interactions and close packing of hydrophobic ligands are the key for the reactivity and stability. The dehydrogenation mechanism is investigated by temperature-programmed desorption, in situ synchrotron PXRD and solid-state NMR.
\end{abstract}

\begin{abstract}
Controlling the reactivity of hydride-based ions in the solid state is important for hydrogen-related functions such as hydrogen $\left(\mathrm{H}_{2}\right)$ storage, heterogeneous hydrogenation catalysis and ion conduction. ${ }^{1-3}$ Hydride-based ions include hydride $\left(\mathrm{H}^{-}\right)$and molecular ions such as borohydride $\left(\mathrm{BH}_{4}{ }^{-}\right)$and alanate $\left(\mathrm{AlH}_{4}{ }^{-}\right)$, and they exhibit a strong electron-donating ability. ${ }^{4}$ The reactive character causes high sensitivity to moisture in the air, and it has been a challenge to design the dual properties of high reactivity of hydrides and air stability in the solid state. For example, the dehydrogenation reactivity and air stability are in a trade-off for $\mathrm{BH}_{4}{ }^{-}$in metal borohydrides (MBHs). Air-stable $\mathrm{NaBH}_{4}$ releases $\mathrm{H}_{2}$ above $500{ }^{\circ} \mathrm{C}$, whereas $\mathrm{Al}\left(\mathrm{BH}_{4}\right)_{3}$ is pyrophoric in contact with moisture in the air, and it releases $\mathrm{H}_{2}$ at $60{ }^{\circ} \mathrm{C} .{ }^{5,6}$ The properties of MBHs are
\end{abstract}

${ }^{a}$ Department of Molecular Engineering, Graduate School of Engineering, Kyoto University, Katsura, Nishikyo-ku, Kyoto 615-8510, Japan

${ }^{b}$ RIKEN-JEOL Collaboration Center, Tsurumi, Yokohama, Kanagawa 230-0045, Japan 'JEOL RESONANCE Inc., Musashino, Akishima, Tokyo 196-8558, Japan

${ }^{d}$ Institute for Integrated Cell-Material Sciences, Institute for Advanced Study, Kyoto University, Yoshida, Sakyo-ku, Kyoto 606-8501, Japan. E-mail: horike@icems. kyoto-u.ac.jp

${ }^{e}$ AIST-Kyoto University Chemical Energy Materials Open Innovation Laboratory (ChEM-OIL), National Institute of Advanced Industrial Science and Technology (AIST), Yoshida-Honmachi, Sakyo-ku, Kyoto 606-8501, Japan

${ }^{f}$ Department of Synthetic Chemistry and Biological Chemistry, Graduate School of Engineering, Kyoto University, Katsura, Nishikyo-ku, Kyoto 615-8510, Japan

${ }^{g}$ Department of Materials Science and Engineering, School of Molecular Science and Engineering, Vidyasirimedhi Institute of Science and Technology, Rayong 21210, Thailand

$\dagger$ Electronic supplementary information (ESI) available. CCDC 1855660-1855667 and 1855670-1855672. For ESI and crystallographic data in CIF or other electronic format see DOI: $10.1039 / \mathrm{c} 9 \mathrm{sc} 00731 \mathrm{~h}$ affected by some parameters of metal ions - electronegativity and ionic radius. ${ }^{7}$ A number of studies to tune the properties of MBHs were made (e.g., mixed metal ion $\mathrm{MBHs},{ }^{8-10}$ hybridization with organic polymers, ${ }^{11}$ and nano-confinement in porous scaffolds $\left.{ }^{12,13}\right)$. The reactivity of $\mathrm{BH}_{4}{ }^{-}$in crystal structures depends on hydrogen-hydrogen interactions (e.g., hydrogen bonding and dihydrogen bonding). ${ }^{\mathbf{1 4 1 5}}$ For the precise tuning of these interactions, we applied coordination polymers (CPs) and metal-organic frameworks (MOFs). ${ }^{16-19}$ Tuning the coordination geometry and reactivity of metal ions or bridging ligands can afford the precise configuration of ions/molecules in CP architectures. CP structures are thought to be constructed with $\mathrm{BH}_{4}{ }^{-}$; however it has been unsuccessful because of the high reactivity of $\mathrm{BH}_{4}{ }^{-}$.

The attempts to incorporate reactive $\mathrm{BH}_{4}{ }^{-}$into CP structures readily lead to the reduction of metal ions or decomposition of organic ligands. There are many reports on polymeric crystal structures consisting of metal ions and bridging $\mathrm{BH}_{4}-{ }^{-20}$ On the other hand, the extended $\mathrm{BH}_{4}{ }^{-}$-based crystal structures constructed from metal ions and organic bridging ligands are limited: $\left(\left[\mathrm{Mg}\left(\mathrm{BH}_{4}\right)_{2} \text { (pyrazine }\right)_{2}\right]$ and $\left[\mathrm{Th}\left(\mathrm{OTer}^{\mathrm{Mes}}\right)_{2}\left(\mathrm{BH}_{4}\right)_{2}\left(4,4^{\prime}-\right.\right.$ bipyridyl)]) were the only examples reported in the Cambridge Crystallographic Data Centre (CCDC) database. ${ }^{21,22}$ As shown in previous studies, neutral $\mathrm{N}$-donor ligands are suitable to incorporate $\mathrm{BH}_{4}{ }^{-}$as a counter anion in CP structures. We then used commercially available $\mathrm{Mg}\left(\mathrm{BH}_{4}\right)_{2}$ and $\mathrm{Ca}\left(\mathrm{BH}_{4}\right)_{2}$ for CP synthesis using neutral $\mathrm{N}$-donor ligands under Ar. The solution reaction using $\mathrm{Mg}\left(\mathrm{BH}_{4}\right)_{2}$ and 4,4'-bipyridyl in acetonitrile (MeCN) afforded a polymeric structure. $\mathrm{Ca}\left(\mathrm{BH}_{4}\right)_{2}$ with poor solubility in organic solvents is not suitable for solution reactions. A solvent-free mechanochemical reaction of $\mathrm{Ca}\left(\mathrm{BH}_{4}\right)_{2}$ and 
pyrazine produced crystalline powder of CP. On the other hand, the synthetic attempts using other pyridyl-based ligands afforded amorphous powder or no solid product. This is because of a weak coordination interaction between hard $\mathrm{Mg}^{2+}$ or $\mathrm{Ca}^{2+}$ and soft N-donor ligands according to Hard and Soft Acids and Bases (HSAB) theory. The theory says that soft transition metal ions (e.g. $\mathrm{Zn}^{2+}$ and $\mathrm{Mn}^{2+}$ ) form stable coordination bonds with $\mathrm{N}$-donor ligands. $\left[\mathrm{PPh}_{4} \mathrm{Zn}\left(\mathrm{BH}_{4}\right)_{3}\right]$ and $\left[\mathrm{Mn}\left(\mathrm{BH}_{4}\right)_{2} \cdot 3 \mathrm{THF}\right] \cdot \mathrm{NaBH}_{4}$ were therefore prepared as starting materials. ${ }^{23}$ Bulky $\mathrm{PPh}_{4}{ }^{+}$ cations were incorporated to increase the solubility of the salt. Transition metal ion-based $\mathrm{MBH}$ precursors successfully form coordination bonds with pyridyl and imidazolate ligands, and $10 \mathrm{CP}$ crystals were isolated as summarized in Fig. 1. In general, the structural analysis from a single crystal for $\mathrm{MBH}$ is difficult, and it is usually hard to determine the exact position of hydrogen atoms in $\mathrm{BH}_{4}{ }^{-} \cdot{ }^{\mathbf{2 4 , 2 5}}$ In the present cases, high-quality single-crystal diffraction data enable us to locate the hydrogen atoms of $\mathrm{BH}_{4}{ }^{-}$in a Fourier map and refine freely without restraints. This is beneficial to understand the local structure of $\mathrm{BH}_{4}{ }^{-}$and the resulting properties.

As shown in Fig. 1, each product is classified according to the local coordination environments at the $\mathrm{M}^{2+}$ center (tetrahedral, trigonal bi-pyramidal and octahedral, where $\mathrm{BH}_{4}{ }^{-}$is assumed to occupy one site). As the coordination number of ligands increases, the $\mathrm{M}-\mathrm{B}$ distance increases (tetrahedral: $2.339 \AA$, trigonal bi-pyramidal: $2.499 \AA$ A, and octahedral: $2.696 \AA$, Table $\mathrm{S} 3 \dagger)$. Electron-donation from $\mathrm{N}$-donor ligands to metal ions decreases the electronic interaction between $\mathrm{M}$ and $\mathrm{BH}_{4}{ }^{-21}$ The coordination mode of $\mathrm{BH}_{4}{ }^{-}$to metal ions was clearly determined, and most of them were bidentate. In addition, $\mathrm{BH}_{4}{ }^{-}$in the structures shows dihydrogen bonding with the hydrogen atoms of bridging ligands. A dihydrogen bond is an interaction between negatively charged hydrogen and positively charged hydrogen (e.g., $\mathrm{B}-\mathrm{H}^{\delta-} \cdots \mathrm{H}^{\delta+}-\mathrm{C}$, normally $<2.4 \AA$ ), and affects the crystal packing and physical properties. ${ }^{26}$ The number of dihydrogen bonds varies in the range of 0 to 3 as summarized in Table S3. $\uparrow$ Four packing structures were observed, one-dimensional (1D) chain $(\mathbf{1}, 2,3,4)$, 1D ladder $(5,6,7,8)$, two-dimensional (2D) bilayer (9) and 2D sheet (10). The CPs with a higher coordination number of the ligands show higher structural dimensionality. 5, 6, 7 and 9 contain MeCN as guest molecules, and the permanent porosity of $\mathbf{5}$ and $\mathbf{6}$ was determined by $\mathrm{N}_{2}$ and $\mathrm{CO}_{2}$ adsorption (Fig. S27 and $\mathrm{S} 28 \dagger$ ).

Bulk powder samples were prepared under the same reaction conditions, and phase purity was confirmed by PXRD and infrared (IR) spectroscopy under Ar (Fig. S24 and S25 $\dagger$ ). The thermal properties were characterized by thermogravimetric analysis (TGA) under Ar (Fig. S26 $\dagger$ ). As various types of chemical environments of $\mathrm{BH}_{4}{ }^{-}$were observed in 1-10, the dependence of the air stability on the local structure was examined. Each powder sample (30 mg) was exposed to humidified air (relative humidity (RH) $50 \%$ at $25{ }^{\circ} \mathrm{C}$, Fig. S29 ${ }^{\dagger}$, and time-course IR spectra and PXRD patterns were recorded to monitor $\mathrm{BH}_{4}{ }^{-}$. Reference $\mathrm{MBHs}, \mathrm{NaBH}_{4}$ and $\mathrm{Mg}\left(\mathrm{BH}_{4}\right)_{2}$ were also evaluated for comparison. After air exposure of $\mathrm{Mg}\left(\mathrm{BH}_{4}\right)_{2}$ for 3 hours, no peak is observed in the $\mathrm{B}-\mathrm{H}$ region in the IR spectrum (Fig. 2A). The broad peak at $3500 \mathrm{~cm}^{-1}$ indicates the hydrolysis of $\mathrm{BH}_{4}{ }^{-}$. Although $\mathrm{NaBH}_{4}$ is considered as an air-stable $\mathrm{MBH}$, it showed deliquescence in 2 hours under the conditions and hydrolyzed to form $\mathrm{Na}_{2}\left[\mathrm{~B}_{4} \mathrm{O}_{5}(\mathrm{OH})_{4}\right] \cdot 3 \mathrm{H}_{2} \mathrm{O}$
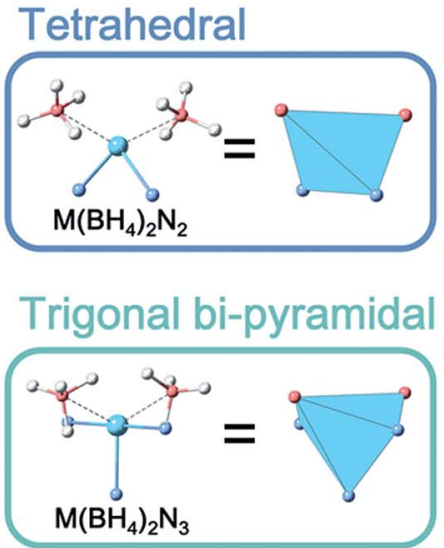

Octahedral

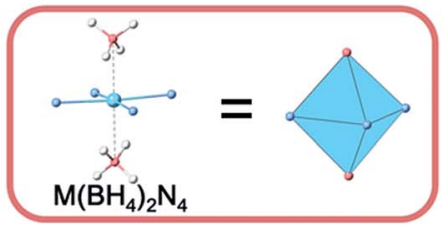

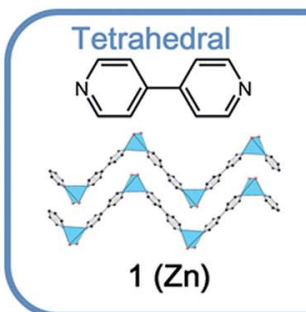
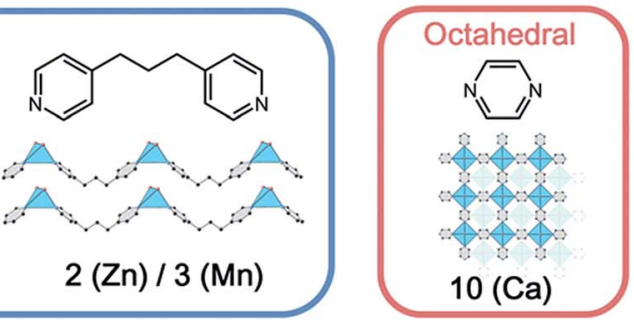

Trigonal bi-pyramidal

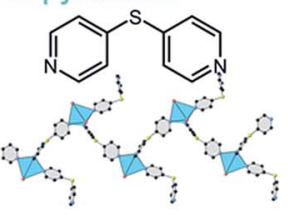

$4(\mathrm{Mn})$
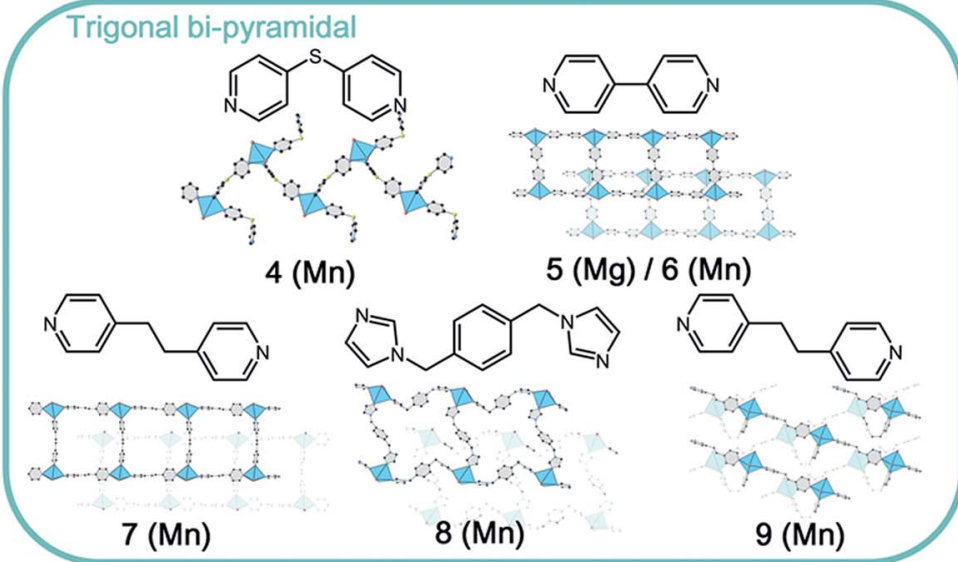

Fig. 1 Crystal structures of $\mathrm{BH}_{4}{ }^{-}$-based CPs. Tetrahedral (1-3), trigonal bi-pyramidal (4-9) and octahedral (10) geometries, and constituent metal ions and ligands are represented, respectively. 

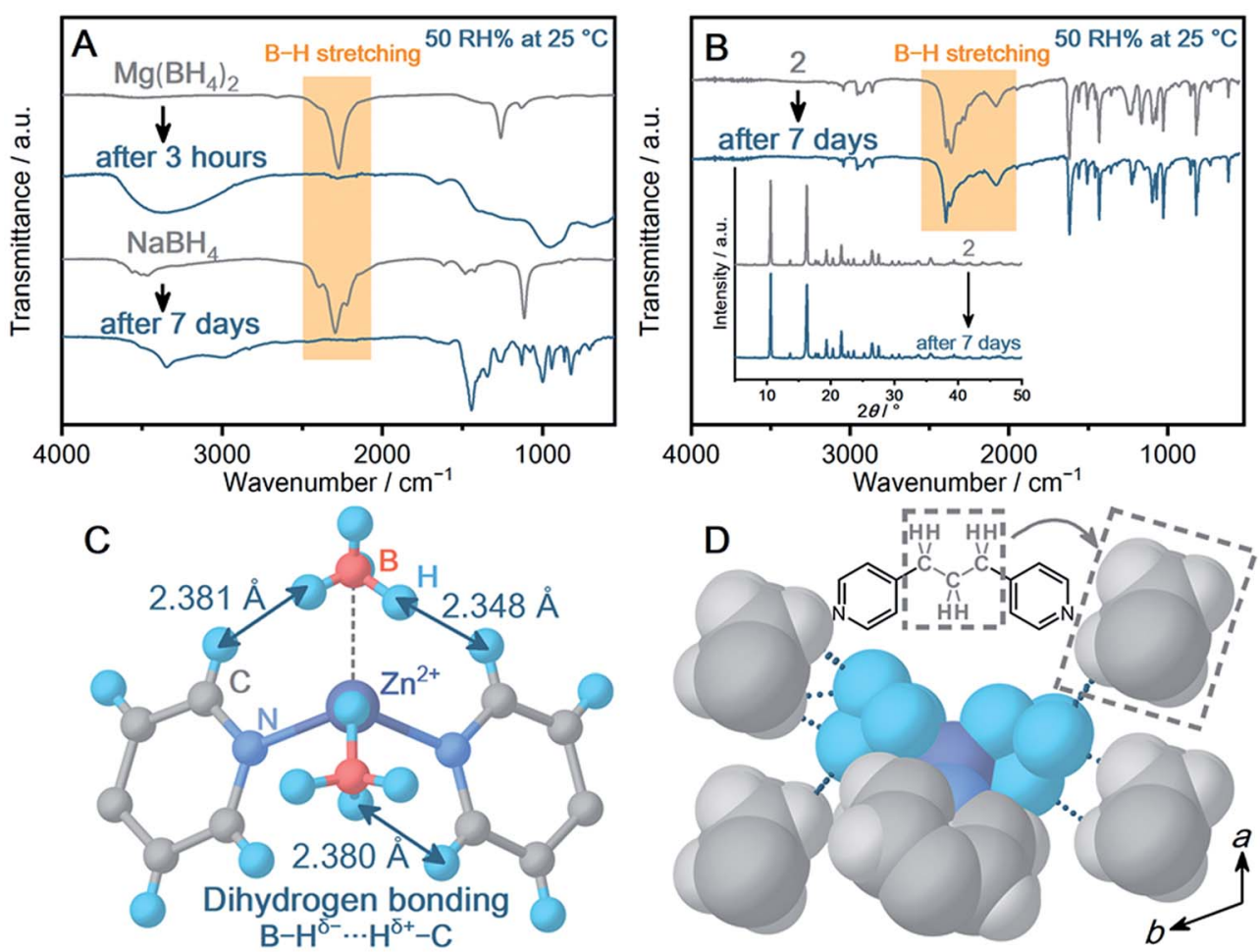

Fig. 2 (A) IR spectra of $\mathrm{Mg}\left(\mathrm{BH}_{4}\right)_{2}$ and $\mathrm{NaBH}_{4}$ before and after the air exposure (50 RH\% at $25^{\circ} \mathrm{C}$ ). (B) IR spectra and PXRD patterns (inset) of 2 before and after the air exposure $\left(50 \mathrm{RH} \%\right.$ at $\left.25^{\circ} \mathrm{C}\right)$ for 7 days. (C) Local coordination geometry of $\mathrm{BH}_{4}{ }^{-}$in 2 from single-crystal $\mathrm{X}$-ray diffraction analysis. The arrows represent the dihydrogen bonds between $\mathrm{B}-\mathrm{H}^{\delta-}$ and $\mathrm{H}^{\delta+}-\mathrm{C}$. (D) Packing structure of 2 . The short contacts between the hydrogen atoms of $\mathrm{BH}_{4}{ }^{-}$and the aliphatic group of the surrounding dpp $\left(-\mathrm{CH}_{2} \mathrm{CH}_{2} \mathrm{CH}_{2}{ }^{-}\right)$are displayed as a blue dotted line. The pyridyl rings of the neighbouring dpp are omitted for clarity.

after air exposure for 7 days (Fig. S30†). Humidified conditions are harsh enough to hydrolyze $\mathrm{BH}_{4}{ }^{-}$in most of the MBHs.

Some crystalline powder samples changed to amorphous in a few minutes $\left(\mathbf{5}, \mathrm{Mg}^{2+}\right.$ and $\left.\mathbf{1 0}, \mathrm{Ca}^{2+}\right)$ or 1 day $\left(3-4,6-9, \mathrm{Mn}^{2+}\right)$. Notably, among the $\mathrm{BH}_{4}{ }^{-}$-CPs, $\mathrm{Zn}^{2+}$-based $\mathrm{CPs}(\mathbf{1}$ and 2$)$ exhibited high air stability. In particular, 2 exhibits IR spectra identical before and after air exposure for 7 days in Fig. 2B. In addition, 2 retains highly crystalline peaks in PXRD (Fig. 2B, inset). The results demonstrate improved air stability of 2 , and the mechanisms are discussed based on the crystal structure of 2. Although many structural parameters affect the air stability, we classify the main contributions to the high air stability of 2 as the (i) metal-ligand coordination bond (ii) dihydrogen bonding and (iii) packing structure. 2 shows higher air stability than the isostructural $\mathrm{Mn}^{2+}$-based 3. In general, a metal-ligand bond is an essential parameter to determine the air stability of $\mathrm{CPs}^{27}$ The $\mathrm{Zn}-\mathrm{N}$ bond in tetrahedral geometry is known to construct highly stable CPs. ${ }^{28}$ Meanwhile, limited examples of CPs with $\mathrm{Mn}-\mathrm{N}$ in tetrahedral geometry have been reported, and most of them are sensitive to air..$^{29,30}$ The tendency of air stability depending on metal ions is also suggested by a survey of the CCDC database. ${ }^{31}$ Fig. 3C displays the dihydrogen bond between $\mathrm{BH}_{4}{ }^{-}$and the neighboring dipyridylpropane (dpp) in the structure of 2 . In addition to the X-ray diffraction analysis, the geometry optimization on 2 utilizing DFT calculation suggests that dihydrogen bonds form as well (Fig. S46†). In general, dihydrogen bonding stabilizes a crystal structure by the electrostatic interaction between oppositely charged hydrogen atoms, ${ }^{32,33}$ and the interaction lowers the electron donating ability of $\mathrm{BH}_{4}{ }^{-}$. The intermolecular interaction and packing structure are also essential for air stability, because they affect the diffusion of $\mathrm{H}_{2} \mathrm{O}$ molecules in the structure. $\mathrm{BH}_{4}{ }^{-}$is surrounded by the hydrophobic propyl group (2.545-3.010 ̊) as shown in Fig. 2D, which avoids the attack of $\mathrm{H}_{2} \mathrm{O}$. In addition, the concentration of hydrophobic species around $\mathrm{BH}_{4}{ }^{-}$of 2 was compared with that of other CPs showing different air stability. The number of carbon atoms away from the boron atoms of $\mathrm{BH}_{4}{ }^{-}$within $5 \AA$ A was counted for 2,9 and 10 (Fig. S47†). 2 shows a higher concentration of carbon atoms than $\mathbf{9}$ and $\mathbf{1 0}$ (the total number of carbon atoms within $5 \AA$, 2: 47, 9: 39, 10: 16), which also contributes to the high air stability of $2 .^{34}$

As 2 exhibited exceptionally high air stability, the dehydrogenation properties of 2 were characterized. The TGA profile under Ar exhibits a characteristic weight loss of $1.4 \mathrm{wt} \%$ at 170 ${ }^{\circ} \mathrm{C}$ with a second weight loss at $260^{\circ} \mathrm{C}$ (Fig. S26 $\dagger$ ). The released chemical species at $170{ }^{\circ} \mathrm{C}$ were analyzed using temperatureprogrammed desorption (TPD) as shown in Fig. 3A. The release of $\mathrm{H}_{2}(\mathrm{mz}=2)$ starts from $108{ }^{\circ} \mathrm{C}$ and peaks are observed at 179 and $203{ }^{\circ} \mathrm{C}$ in the TPD profile, corresponding to the weight loss $(1.4 \mathrm{wt} \%)$ at $170{ }^{\circ} \mathrm{C}$ in TGA. The observed dehydrogenation temperature for 2 is higher than that of $\left[\mathrm{NaZn}\left(\mathrm{BH}_{4}\right)_{3}\right]\left(103{ }^{\circ} \mathrm{C}\right),{ }^{8}$ which is due to the stabilization effect of $\mathrm{BH}_{4}{ }^{-}$in 2 . In spite of 


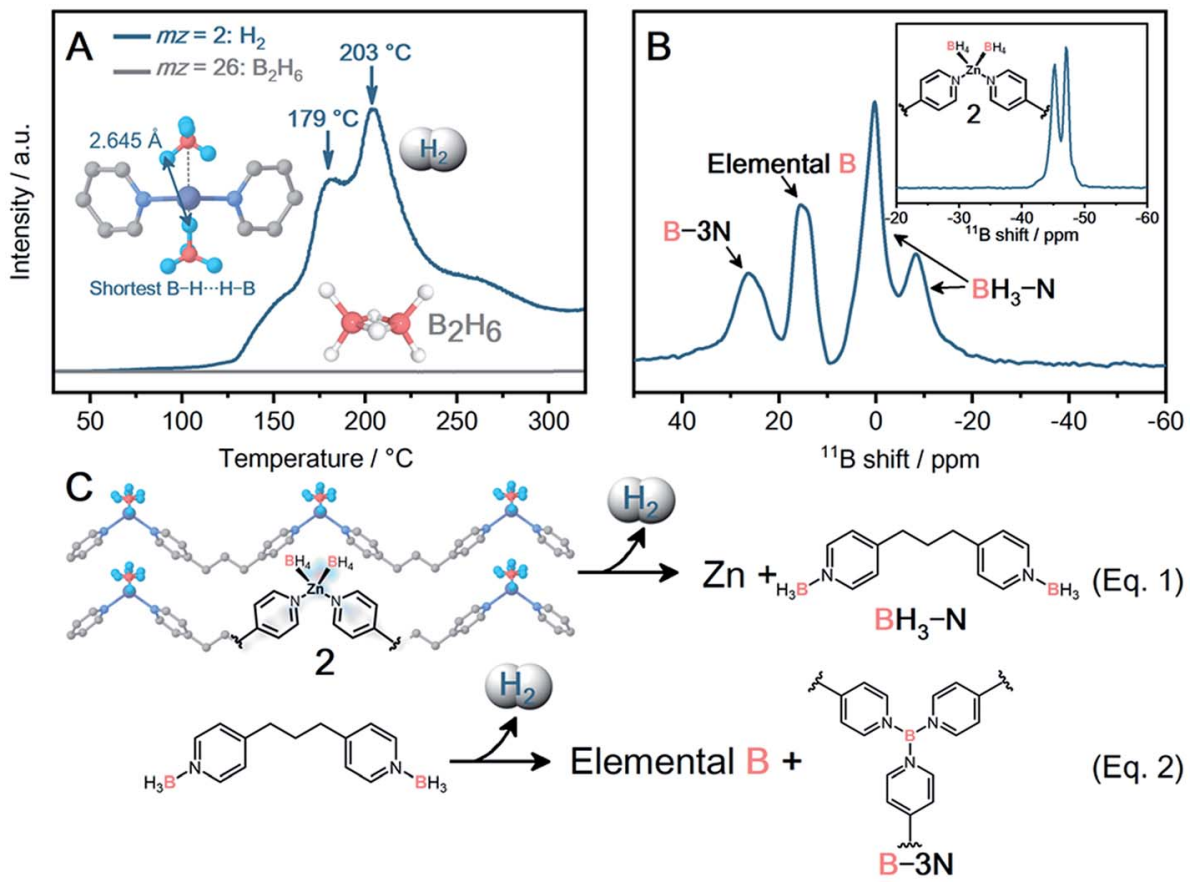

Fig. 3 (A) TPD profile of 2 under Ar. The release of $\mathrm{H}_{2}$ (blue line) and $\mathrm{B}_{2} \mathrm{H}_{6}$ (gray line) was monitored. Inset: the shortest $\mathrm{B}-\mathrm{H} \cdots \mathrm{H}-\mathrm{B}$ distance is displayed. (B) Solid-state ${ }^{11} \mathrm{~B}$ MAS NMR spectra of 2 before (inset) and after dehydrogenation. (C) Schematic illustration of the proposed dehydrogenation mechanism of 2 .

the higher air stability of 2 than $\mathrm{NaBH}_{4}, 2$ exhibits a lower dehydrogenation temperature than $\mathrm{NaBH}_{4}\left(170\right.$ vs. $\left.505{ }^{\circ} \mathrm{C}\right)$. Note that dpp ligands decrease the amount of $\mathrm{H}_{2}$ release per weight, and the $1.4 \mathrm{wt} \%$ of $\mathrm{H}_{2}$ is smaller than that of the MBHs. The close contact of each $\mathrm{BH}_{4}{ }^{-}$enables dehydrogenation at a lower temperature. The inset of Fig. 3A displays the closest distance between $\mathrm{B}-\mathrm{H} \cdots \mathrm{H}-\mathrm{B}(2.645 \AA)$, which is comparable to that of $\mathrm{Zn}^{2+}$-based MBHs ([LiZn $\left.{ }_{2}\left(\mathrm{BH}_{4}\right)_{5}\right]$ : $2.482 \AA$; [NaZn $\left.\left(\mathrm{BH}_{4}\right)_{3}\right]$ : $2.291 \AA) .{ }^{8}$ Tetrahedral geometry in 2 is suitable to arrange $\mathrm{BH}_{4}{ }^{-}$ in close proximity. The variable temperature synchrotron PXRD experiments indicate the structural expansion of 2 upon heating $\left(25-226^{\circ} \mathrm{C}\right.$, Fig. S38 and S39†). 2 does not exhibit an amorphous phase before dehydrogenation at $179{ }^{\circ} \mathrm{C}$, and metallic $\mathrm{Zn}$ peaks are observed above $180{ }^{\circ} \mathrm{C}$. The dehydrogenation of two $\mathrm{BH}_{4}{ }^{-}$ produces one molecule of $\mathrm{H}_{2}$ and subsequently reduces $\mathrm{Zn}^{2+}$ to metallic $\mathrm{Zn}$.

The environment of $\mathrm{BH}_{4}{ }^{-}$after the dehydrogenation was characterized by solid-state ${ }^{11} \mathrm{~B}$ magic angle spinning (MAS) nuclear magnetic resonance (NMR). The ${ }^{11} \mathrm{~B}$ NMR spectrum of pristine 2 shows two peaks at -45 and $-47 \mathrm{ppm}$, and both peaks correspond to crystallographically independent $\mathrm{BH}_{4}{ }^{-}$ (Fig. 3B, inset). ${ }^{8}$ The dehydrogenized 2 displays ${ }^{11} \mathrm{~B}$ peaks at -8 , 0,15 , and $30 \mathrm{ppm}$ in Fig. $3 \mathrm{~B}$, and was further characterized by using the 2D multi-quantum (MQ) MAS NMR spectrum (Fig. S42†). To identify the resultant boron species, a $2 \mathrm{D}{ }^{1} \mathrm{H}-$ $\left\{{ }^{11} \mathrm{~B}\right\}$ through-bond heteronuclear multiple quantum coherence (HMQC) experiment was performed (Fig. S43 $\dagger$ ). The ${ }^{11} \mathrm{~B}$ peaks observed at -8 and $0 \mathrm{ppm}$ correlate with the proton at $2 \mathrm{ppm}$, indicative of a $\mathrm{B}-\mathrm{H}$ bond. These boron species are assigned to the $\left[\left(\mathrm{BH}_{3}\right)_{2} \mathrm{dpp}\right]$ complexes. ${ }^{35}$ Meanwhile, the remaining two ${ }^{11} \mathrm{~B}$ peaks $(15,30 \mathrm{ppm})$ do not exhibit a clear correlation, indicating no direct bond between these boron species and hydrogen atoms. The ${ }^{11} \mathrm{~B}$ peak at $15 \mathrm{ppm}$ corresponds to elemental boron and matches well with the simulated one (Fig. S44†), while the ${ }^{11} \mathrm{~B}$ peak at $30 \mathrm{ppm}$ corresponds to $\mathrm{B}-3 \mathrm{~N}$ species (e.g., $\left.\left[\mathrm{B}(\mathrm{dpp})_{x}\right]\right) .{ }^{36-38}$ The $2 \mathrm{D}{ }^{1} \mathrm{H} /{ }^{13} \mathrm{C}$ heteronuclear correlation spectrum clearly exhibits the ${ }^{1} \mathrm{H}$ and ${ }^{13} \mathrm{C}$ peaks corresponding to the aromatic ring and aliphatic chain of dpp, indicating that dpp does not decompose during dehydrogenation (Fig. S45†).

The first peak of $\mathrm{H}_{2}$ release at $179{ }^{\circ} \mathrm{C}$ in TPD corresponds to the dehydrogenation of $\mathrm{BH}_{4}{ }^{-}$(eqn (1)). The release of toxic $\mathrm{B}_{2} \mathrm{H}_{6}$ is suppressed by the complexation with the $\mathrm{N}$-donor dpp ligand to form $\left[\left(\mathrm{BH}_{3}\right)_{2} \mathrm{dpp}\right]$ as revealed by solid-state NMR and IR spectra (Fig. S40†). The second peak of $\mathrm{H}_{2}$ release at $203{ }^{\circ} \mathrm{C}$ in TPD corresponds to the further dehydrogenation of $\left[\left(\mathrm{BH}_{3}\right)_{2} \mathrm{dpp}\right]$. Solid-state NMR suggests that $\left[\left(\mathrm{BH}_{3}\right)_{2} \mathrm{dpp}\right]$ partly forms elemental boron and $\mathrm{B}-3 \mathrm{~N}$ species such as $\left[\mathrm{B}(\mathrm{dpp})_{x}\right]$ through the dehydrogenation (eqn (2)). 2 arranged $\mathrm{BH}_{4}{ }^{-}$and nitrogen atoms of dpp close to each other in a $1: 1$ ratio $(\mathrm{B} \cdots \mathrm{N}$ distance: 3.450 and $3.462 \AA$, Fig. S35†). 2 maintains the crystal structure before dehydrogenation at $179^{\circ} \mathrm{C}$ as observed by in situ PXRD. The results indicate that the pre-organized environment of $\mathrm{BH}_{4}{ }^{-}$in 2 is preserved before the dehydrogenation, leading to the release of pure $\mathrm{H}_{2}$ without $\mathrm{B}_{2} \mathrm{H}_{6}$.

\section{Conclusions}

By considering suitable combinations of metal ions and $\mathrm{N}$ donor ligands, we have constructed 10 coordination polymer crystals involving reactive $\mathrm{BH}_{4}{ }^{-}$with various coordination 
geometries. In particular, [ $\mathrm{Zn}\left(\mathrm{BH}_{4}\right)_{2}$ (dipyridylpropane)] (2) demonstrated both high dehydrogenation reactivity and high air stability. The crystal structure of 2 was intact under humidified conditions (50 $\mathrm{RH} \%$ at $25{ }^{\circ} \mathrm{C}, 7$ days) which indicates exceptionally high air stability as compared with conventional MBHs. This is due to the strong metal-ligand bond, the electrostatic stabilization by dihydrogen bonding, and close packing of the hydrophobic group with $\mathrm{BH}_{4}{ }^{-}$. In spite of the stabilization of $\mathrm{BH}_{4}{ }^{-}$, the dehydrogenation reactivity was maintained (pure $\mathrm{H}_{2}, 1.4 \mathrm{wt} \%, 179^{\circ} \mathrm{C}$ ). Tetrahedral geometry in 2 arranged two $\mathrm{BH}_{4}{ }^{-}$closely, which accelerated the dehydrogenation. We demonstrated that crystal engineering of coordination polymers and metal-organic frameworks expands the library of hydride-based crystal structures and their properties.

\section{Conflicts of interest}

There are no conflicts to declare.

\section{Acknowledgements}

The authors thank Dr Hiroyasu Sato from RIGAKU Corporation and Ms Nanae Shimanaka for their assistance in solving the crystal structure. The authors thank Dr Shogo Kawaguchi at the Super Photon Ring (SPring-8) for the synchrotron PXRD measurements. The work was supported by the Japan Society of the Promotion of Science (JSPS) for a Grant-in-Aid for Scientific Research (B) (JP18H02032) from the Ministry of Education, Culture, Sports, Science and Technology, Japan, and Strategic International Collaborative Research Program (SICORP) and Adaptable and Seamless Technology Transfer Program through Target-driven R\&D (A-STEP) from the Japan Science and Technology, Japan.

\section{References}

1 T. He, P. Pachfule, H. Wu, Q. Xu and P. Chen, Nat. Rev. Mater., 2016, 1, 16059.

2 G. Kobayashi, Y. Hinuma, S. Matsuoka, A. Watanabe, M. Iqbal, M. Hirayama, M. Yonemura, T. Kamiyama, I. Tanaka and R. Kanno, Science, 2016, 351, 1314-1317.

3 M. Kitano, Y. Inoue, Y. Yamazaki, F. Hayashi, S. Kanbara, S. Matsuishi, T. Yokoyama, S.-W. Kim, M. Hara and H. Hosono, Nat. Chem., 2012, 4, 934-940.

4 Z. M. Heiden and A. P. Lathem, Organometallics, 2015, 34, 1818-1827.

5 J. F. Mao and D. H. Gregory, Energies, 2015, 8, 430-453.

6 Y. Nakamori, H. W. Li, K. Kikuchi, M. Aoki, K. Miwa, S. Towata and S. Orimo, J. Alloys Compd., 2007, 446-447, 296-300.

7 Y. Nakamori, K. Miwa, A. Ninomiya, H. Li, N. Ohba, S. Towata, A. Züttel and S. Orimo, Phys. Rev. B: Condens. Matter Mater. Phys., 2006, 74, 045126.

8 D. Ravnsbæk, Y. Filinchuk, Y. Cerenius, H. J. Jakobsen, F. Besenbacher, J. Skibsted and T. R. Jensen, Angew. Chem., Int. Ed., 2009, 121, 6787-6791.
9 T. Jaroń, P. A. Orłowski, W. Wegner, K. J. Fijałkowski, P. J. Leszczyński and W. Grochala, Angew. Chem., Int. Ed., 2015, 54, 1236-1239.

10 R. Černý, P. Schouwink, Y. Sadikin, K. Stare, L. u. Smrčok, B. Richter and T. R. Jensen, Inorg. Chem., 2013, 52, 99419947.

11 J. Huang, Y. Yan, L. Ouyang, H. Wang, J. Liu and M. Zhu, Dalton Trans., 2014, 43, 410-413.

12 E. Callini, P. Á. Szilágyi, M. Paskevicius, N. P. Stadie, J. Réhault, C. E. Buckley, A. Borgschulte and A. Züttel, Chem. Sci., 2016, 7, 666-672.

13 P. N. Suwarno, A. Nale, T. M. Eggenhuisen, M. Oschatz, J. P. Embs, A. Remhof and P. E. de Jongh, J. Phys. Chem. C, 2017, 121, 4197-4205.

14 R. Custelcean and J. E. Jackson, Chem. Rev., 2001, 101, 19631980.

15 D. J. Wolstenholme, J. L. Dobson and G. S. McGrady, Dalton Trans., 2015, 44, 9718-9731.

16 O. M. Yaghi, M. O'Keeffe, N. W. Ockwig, H. K. Chae, M. Eddaoudi and J. Kim, Nature, 2003, 423, 705-714.

17 S. Kitagawa, R. Kitaura and S. Noro, Angew. Chem., Int. Ed., 2004, 43, 2334-2375.

18 G. Ferey, Chem. Soc. Rev., 2008, 37, 191-214.

19 S. R. Batten, N. R. Champness, X.-M. Chen, J. GarciaMartinez, S. Kitagawa, L. Öhrström, M. O'Keeffe, M. Paik Suh and J. Reedijk, Pure Appl. Chem., 2013, 85, 1715-1724.

20 V. D. Makhaev, Russ. Chem. Rev., 2000, 69, 727-746.

21 M. J. Ingleson, J. P. Barrio, J. Bacsa, A. Steiner, G. R. Darling, J. T. A. Jones, Y. Z. Khimyak and M. J. Rosseinsky, Angew. Chem., Int. Ed., 2009, 48, 2012-2016.

22 J. McKinven, G. S. Nichol and P. L. Arnold, Dalton Trans., 2014, 43, 17416-17421.

23 V. D. Makhaev, A. P. Borisov, T. P. Gnilomedova, É. B. Lobkovskii and A. N. Chekhlov, Bull. Acad. Sci. USSR, Div. Chem. Sci., 1987, 36, 1582-1586.

24 Y. Filinchuk, R. Černý and H. Hagemann, Chem. Mater., 2009, 21, 925-933.

25 Y. Filinchuk, D. Chernyshov and R. Cerny, J. Phys. Chem. C, 2008, 112, 10579-10584.

26 N. V. Belkova, L. M. Epstein, O. A. Filippov and E. S. Shubina, Chem. Rev., 2016, 116, 8545-8587.

27 N. C. Burtch, H. Jasuja and K. S. Walton, Chem. Rev., 2014, 114, 10575-10612.

28 K. S. Park, Z. Ni, A. P. Cote, J. Y. Choi, R. Huang, F. J. UribeRomo, H. K. Chae, M. O'Keeffe and O. M. Yaghi, Proc. Natl. Acad. Sci. U. S. A., 2006, 103, 10186-10191.

29 K. Kadota, E. Sivaniah, S. Bureekaew, S. Kitagawa and S. Horike, Inorg. Chem., 2017, 56, 8744-8747.

$30 \mathrm{~K}$. Müller-Buschbaum and F. Schonfeld, CSD Communication, 2014.

31 In CCDC database, the reported examples of $\left[\mathrm{Zn}(\mathrm{X})_{2}(\text { pyridyl })_{2}\right]$ are greater than twice of the hydrated geometry, $\left[\mathrm{Zn}(\mathrm{X})_{2}(\text { pyridyl })_{2}\left(\mathrm{H}_{2} \mathrm{O}\right)_{2}\right]$ (1306 vs. 814 hits). By contrast, $\mathrm{Mn}^{2+}$ prefers the hydrated structure (unhydrated: 28 hits, hydrated: 375 hits). 
32 J. Fanfrlik, M. Lepsik, D. Horinek, Z. Havlas and P. Hobza, ChemPhysChem, 2006, 7, 1100-1105.

33 I. V. Glukhov, K. A. Lyssenko, A. A. Korlyukov and M. Y. Antipin, Russ. Chem. Bull., 2005, 54, 547-559.

34 X. Zhao, H. Yang, E. T. Nguyen, J. Padilla, X. Chen, P. Feng and X. Bu, J. Am. Chem. Soc., 2018, 140, 13566-13569.

35 P. Veeraraghavan Ramachandran, A. S. Kulkarni, Y. Zhao and J. Mei, Chem. Commun., 2016, 52, 11885-11888.
36 G. Xia, Q. Gu, Y. Guo and X. Yu, J. Mater. Chem., 2012, 22, 7300-7307.

37 C. L. Turner, R. E. Taylor and R. B. Kaner, J. Phys. Chem. C, 2015, 119, 13807-13813.

38 P. M. I. Irene, A. C. Armando and C. Rosalinda, Magn. Reson. Chem., 1993, 31, 189-193. 